International Journal of Advanced Chemistry, $8(1)(2020) 180-188$
International Journal of Advanced Chemistry
SPC
Website: www.sciencepubco.com/index.php/IJAC
Research paper

\title{
Quantum chemical analysis of harmful dye 3-[ (4-anilinophenyl) diazenyl] benzenesulfonate, metanil yellow
}

\author{
Shreyas Parbat* \\ Department of Chemical Engineering, Indian Institute of Science, Bangalore, India \\ *Corresponding author E-mail: shreyasparbat2120@gmail.com
}

\begin{abstract}
In the present work, quantum chemical study of the harmful dye, metanil yellow is conducted. The optimized molecular geometry and harmonic vibrational frequencies of metanil yellow were calculated by DFT-B3LYP method with LANL2DZ basis set. The vibrational assignments were performed on the basis of the potential energy distribution (PED) of the vibrational modes. Infrared spectra and Bulk Raman spectra were also obtained and characteristic peaks for the title compound were studied. The nonlinear optical properties of the title compound were calculated and discussed. Dipole moment, polarizability and first-order hyperpolarizability of the title compound were reported in order to study nonlinear optical properties (NLO). HOMO-LUMO energy levels were also computed in order to get the bandgap energy. Global reactivity descriptors were calculated using the HOMO and LUMO to predict compound reactivity. UV-Vis spectrum of the title compound was calculated using TD-DFT method. The molecular orbital contributions were studied by density of states (DOSs). Mulliken atomic charges and atomic polar tensors (APT) on each atom were tabulated. A discussion of the vibrational energy of each mode is also presented in this article.
\end{abstract}

Keywords: DFT; Gaussian; Metanil Yellow; Nonlinear Optical Properties; Raman Spectra.

\section{Introduction}

Metanil yellow is an azo dye having yellow colour which is prepared by diazotization reaction and a coupling reaction. In recent times, metanil yellow have succeeded in achieving great attention due to its useful behaviour in the food industries. These kinds of dyes are used as food additives and food colorants. It is used as food adulterant in turmeric powder and various dals in India (Dhakal et al. 2016, Common food adulterants in India 2018). The title compound is used in coloring wool, detergent, paper, etc. It is a cheap colorant (Nath et al. 2016). Although, the title compound has gotten various wide applications in food industry, it belongs to the "nonpermitted" category of the food color (Ghosh et al. 2017). Even if metanil yellow has been used widely, it is proved that deliberate or indeliberate consumption can cause the damage to human body systems such as nervous system, digestive system, cardiovascular system as well as reproductive system (Ghosh et al. 2017). Experiments performed on several animals such as goat liver (Hazra et al. 2016) and rats (Sarkar et al. 2013) proved that the intake of the title compound is harmful. Consumption of this dye by any mean is quite risky for human health (Das et al. 1997). Hence, the proper quantum chemical study of this harmful dye is essential.

The structure of the metanil yellow was studied using Density Functional Theory (DFT) with B3LYP hybrid exchange correlation functional and LANL2DZ basis set. Potential Energy Distribution (PED) was studied by performing vibrational assignments. The B3LYP functional and LANL2DZ basis set of Density Functional Theory (DFT) helped us to investigate HOMO and LUMO molecular orbitals of metanil yellow. Non-Linear optic activity of metanil yellow was demonstrated by obtaining linear polarizability, hyperpolarizability and dipole moment. Atomic polar tensors (APT) and Mulliken atomic charge on each atom were obtained by Density Functional Theory method. UV-Vis spectra, IR spectra, Raman spectra were also computed in order to obtain the exact position of atoms present in title compound. The density of state (DOS) and its energies were also computed. Vibrational energy and contribution of each mode towards the potential energy of the molecule is reported.

\section{Computational details}

For meeting the requirements of both accuracy and computing economy, theoretical methods and basis sets should be considered. DFT has proved to be extremely useful in treating the electronic structure of molecules (Arivazhagan \& Jeyavijayan 2011). Calculations were carried out theoretically with the help of Gaussian (Frisch et al. 2009) program package installed in Tyrone cluster of Super Computer Research Centre (SERC) of Indian Institute of Science (IISc), Bangalore, India. Gaussian software has various preinstalled exchange correlation functional. Becke's three parameter hybrid functional with Lee-Yang-Parr correction (Lee et al. 1988) that is, B3LYP hybrid 
functional (Becke et al. 1993) and LANL2DZ basis set (Dunning \& Hay 1977, Hay \& Wadt 1985) was used. The molecular structure of metanil yellow was drawn in GaussView 5.0.8 (Frisch et al. 2009) program and it is shown in Fig. 1. Geometrical optimization was performed by relaxing and converging the geometry of the molecule. This converged and optimized geometry corresponds to true minimum, as revealed by the lack of imaginary values in wavenumber calculations. The HOMO-LUMO molecular orbital levels, electrostatic potentials and Van der walls surfaces were visualized using Avogadro program (Hanwel et al. 2012). The theoretical vibrational spectra and contribution of each mode towards potential energy were interpreted using VEDA 4 program (Jamroz 2004). Ultraviolet-visible spectrum and Density of State (DOS) diagram were obtained by using GaussSum program (O'Boyle et al. 2008). This program helps to calculate the contribution of group towards the molecular orbitals. The electronic population of each atom was determined and it contributed towards the determination of Mulliken atomic charges and atomic polar tensors (APT) (Ferreira 1993). The Gaussian program helps in getting the values of dipole moment, polarizability and first-order hyperpolarizability. These values were also obtained using DFTB3LYP functional and LANL2DZ basis set. The final value of total polarizability and first-order hyperpolarizability were calculated theoretically using equations (1-3).

$\mu=\left(\mu_{\mathrm{x}}^{2}+\mu_{\mathrm{y}}^{2}+\mu_{\mathrm{z}}^{2}\right)^{1 / 2}$

$\alpha_{\mathrm{tot}}=\left(\alpha_{\mathrm{xx}}+\alpha_{\mathrm{yy}}+\alpha_{\mathrm{zz}}\right) / 3$

$\beta_{\mathrm{tot}}=\left[\left(\beta_{\mathrm{xxx}}+\beta_{\mathrm{xyy}}+\beta_{\mathrm{xzz}}\right)^{2}+\left(\beta_{\mathrm{xxy}}+\beta_{\mathrm{yyy}}+\beta_{\mathrm{yzz}}\right)^{2}+\left(\beta_{\mathrm{xxz}}+\beta_{\mathrm{yyz}}+\beta_{\mathrm{zzz}}\right)^{2}\right]^{1 / 2}$

In closed shell Hartree-Fock theory, the negative of the HOMO energy represents ionization potential (I) (Koopmans \& Tjalling 1934) and negative of LUMO represent electron affinity (A) (Zhang et al. 2007). The values of electronegativity ( $\chi$ ) (Parr et al. 1978, Parr \& Pearson 1983), electrophilicity index ( $\omega)$ (Parr et al. 1999), chemical potential ( $\mu$ ), hardness ( $\eta$ ) (Pearson 2005), softness (S) etc. for metanil yellow can be calculated theoretically using equations (4-8).

$$
\begin{aligned}
& \mu=-(\mathrm{I}+\mathrm{A}) / 2 \\
& \chi=(\mathrm{I}+\mathrm{A}) / 2 \\
& \eta=(\mathrm{I}-\mathrm{A}) / 2 \\
& \mathrm{~S}=\eta / 2 \\
& \omega=\mu^{2} / 2 \eta
\end{aligned}
$$

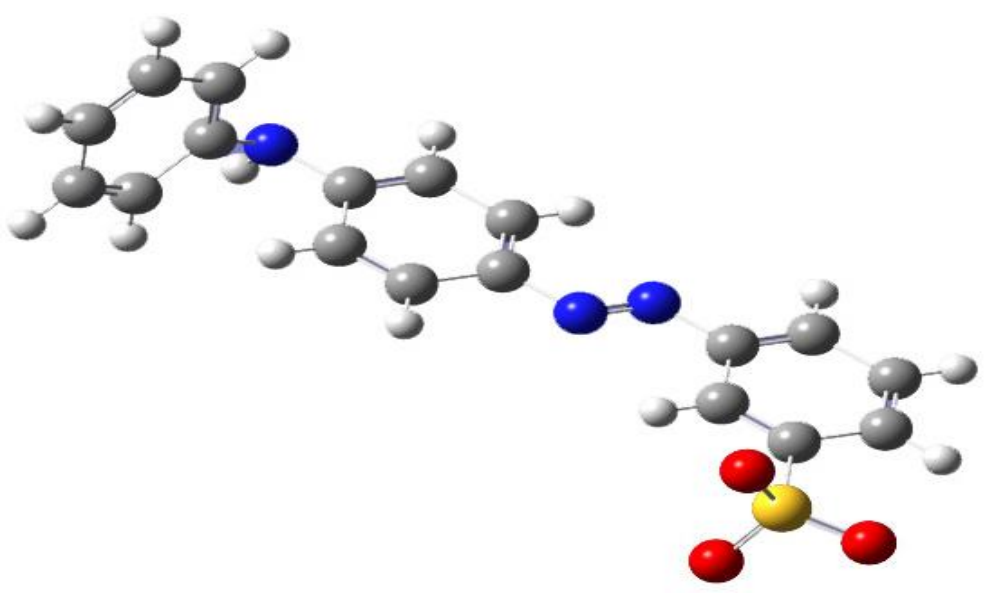

Fig. 1: Metanil Yellow.

\section{Results and discussion}

\subsection{Geometrically optimized structure}

The optimized molecular structure of metanil yellow along with numbering of each atom is shown in Fig. 2. DFT-B3LYP/ LANL2DZ method was used for obtaining the optimized geometry of metanil yellow. The optimized geometrical parameters of the title compound such as bond lengths, bond angles and dihedral angles are listed in Table 1. The other parameters of the title compound can be calculated from the calculated geometric parameters. The geometric optimized structure of metanil yellow reveals that the meta-substituted azo group is in planar with two benzene rings. The azo bond and $\mathrm{SO}_{3}$ group which are known for their strong electron withdrawing nature, are expected to increase the contribution of the resonance structure. The electronic effect of azo bond contributes to increasing bond length of meta-substituted $\mathrm{SO}_{3}$ group with $\mathrm{C} 2-\mathrm{S} 11$ bond length of $1.9016 \mathrm{~A}^{\circ}$. The bond length of azo bond that is, N15-N16 bond length is $1.292 \mathrm{~A}^{\circ}$ and the dihedral angle of $\mathrm{C} 4-\mathrm{N} 15-\mathrm{N} 16-\mathrm{C} 17$ is found out to be $-179.8752^{\circ}$. The C24-N27 and N27-C29 bond lengths are not the same. The ring carbon atoms in substituted benzenes exert a larger attraction on the valence electron cloud of the hydrogen atom resulting in an increase in the $\mathrm{C}-\mathrm{H}$ force constants and a decrease in the corresponding bond length. 


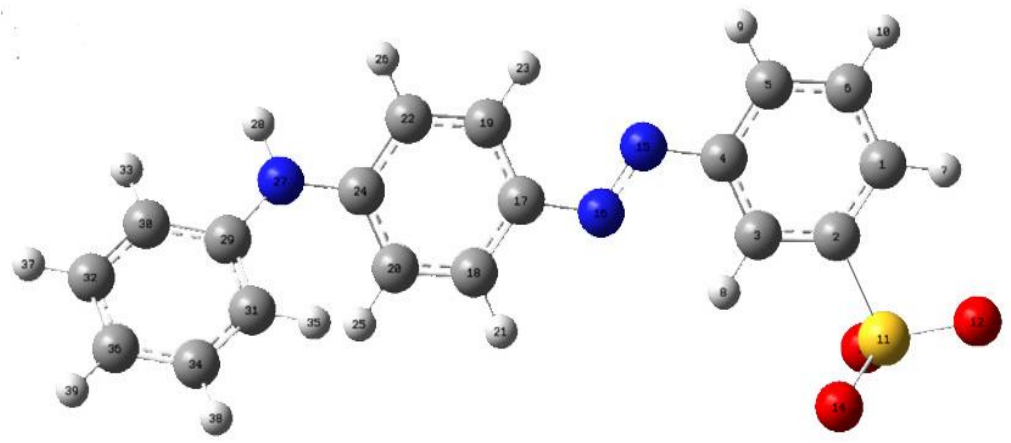

Fig. 2: Geometrically Optimized Structure of Metanil Yellow.

Table 1: Optimized Geometry of Metanil Yellow

\begin{tabular}{|c|c|c|c|c|c|}
\hline Atoms & Bond Length $\left(\mathrm{A}^{\circ}\right)$ & Atoms & Bond Angle $\left({ }^{\circ}\right)$ & Atoms & Dihedral Angle $\left({ }^{\circ}\right)$ \\
\hline $\mathrm{C} 1-\mathrm{C} 2$ & 1.4047 & C2-C1-C6 & 119.1324 & C6-C1-C2-C3 & -0.8694 \\
\hline C1-C6 & 1.4089 & $\mathrm{C} 2-\mathrm{C} 1-\mathrm{H} 7$ & 118.4966 & C6-C1-C2-S11 & 179.0886 \\
\hline C1-H7 & 1.0871 & C6-C1-H7 & 122.3561 & $\mathrm{H} 7-\mathrm{C} 1-\mathrm{C} 2-\mathrm{C} 3$ & 177.7577 \\
\hline C2-S11 & 1.9016 & C1-C2-S11 & 118.254 & C2-C1-C6-C5 & 0.1498 \\
\hline $\mathrm{C} 3-\mathrm{C} 4$ & 1.4184 & C3-C2-S11 & 119.5743 & C2-C1-C6-H10 & 179.9558 \\
\hline C3-H8 & 1.0854 & $\mathrm{C} 2-\mathrm{C} 3-\mathrm{C} 4$ & 118.4382 & $\mathrm{H} 7-\mathrm{C} 1-\mathrm{C} 6-\mathrm{C} 5$ & -178.4218 \\
\hline $\mathrm{C} 4-\mathrm{C} 5$ & 1.4145 & $\mathrm{C} 2-\mathrm{C} 3-\mathrm{H} 8$ & 120.6398 & H7-C1-6-H10 & 1.3843 \\
\hline C4-N15 & 1.4273 & $\mathrm{C} 4-\mathrm{C} 3-\mathrm{H} 8$ & 120.9116 & $\mathrm{C} 1-\mathrm{C} 2-\mathrm{C} 3-\mathrm{C} 4$ & 0.8995 \\
\hline C5-C6 & 1.4043 & $\mathrm{C} 3-\mathrm{C} 4-\mathrm{C} 5$ & 120.1787 & $\mathrm{C} 1-\mathrm{C} 2-\mathrm{C} 3-\mathrm{H} 8$ & -177.9426 \\
\hline $\mathrm{C} 5-\mathrm{H} 9$ & 1.0872 & C3-C4-N15 & 124.8249 & $\mathrm{~S} 11-\mathrm{C} 2-\mathrm{C} 3-\mathrm{C} 4$ & -179.0579 \\
\hline C6-H10 & 1.0878 & C5-C4-N15 & 114.9963 & $\mathrm{~S} 11-\mathrm{C} 2-\mathrm{C} 3-\mathrm{H} 8$ & 2.1 \\
\hline $\mathrm{S} 11-\mathrm{O} 12$ & 1.6504 & C4-C5-C6 & 120.1609 & C1-C2-S11-O12 & 25.4859 \\
\hline S11-O13 & 1.6465 & $\mathrm{C} 4-\mathrm{C} 5-\mathrm{H} 9$ & 118.2443 & C1-C2-S11-O13 & -93.7428 \\
\hline S11-O14 & 1.6469 & $\mathrm{C} 6-\mathrm{C} 5-\mathrm{H} 9$ & 121.5925 & C1-C2-S11-O14 & 146.3822 \\
\hline $\mathrm{N} 15-\mathrm{N} 16$ & 1.292 & $\mathrm{C} 1-\mathrm{C} 6-\mathrm{C} 5$ & 119.9106 & C3-C2-S11-O12 & -154.555 \\
\hline N16-C17 & 1.4279 & C1-C6-H10 & 120.0281 & C3-C2-S11-O13 & 86.2163 \\
\hline C17-C19 & 1.4178 & $\mathrm{C} 2-\mathrm{S} 11-\mathrm{O} 12$ & 102.2834 & $\mathrm{C} 2-\mathrm{C} 3-\mathrm{C} 4-\mathrm{C} 5$ & -0.2236 \\
\hline $\mathrm{C} 18-\mathrm{C} 20$ & 1.4019 & C2-S11-O13 & 104.3134 & C2-C3-C4-N15 & 179.8777 \\
\hline $\mathrm{C} 18-\mathrm{H} 21$ & 1.0865 & C2-S11-O14 & 103.2755 & H8-C3-C4-C5 & 178.6152 \\
\hline $\mathrm{C} 19-\mathrm{C} 22$ & 1.3964 & O12-S11-O13 & 114.1867 & H8-C3-C4-N15 & -1.2835 \\
\hline $\mathrm{C} 19-\mathrm{H} 23$ & 1.0855 & O12-S11-O14 & 116.07 & C3-C4-C5-C6 & -0.4652 \\
\hline C20-C24 & 1.4159 & O13-S11-O14 & 114.3921 & $\mathrm{C} 3-\mathrm{C} 4-\mathrm{C} 5-\mathrm{H} 9$ & -179.9251 \\
\hline C20-H25 & 1.0844 & C4-N15-N16 & 115.9768 & N15-C4-C5-C6 & 179.443 \\
\hline C22-C24 & 1.4212 & N15-N16-C17 & 115.118 & N15-C4-C5-H9 & -0.0168 \\
\hline C22-H26 & 1.0896 & N16-C17-C18 & 115.8107 & C3-C4-N15-N16 & 0.5149 \\
\hline C24-N27 & 1.4138 & N16-C17-C19 & 125.283 & C5-C4-N15-N16 & -179.3885 \\
\hline N27-H28 & 1.0133 & C18-C17-C19 & 118.9053 & C4-C5-C6-C1 & 0.5005 \\
\hline N27-C29 & 1.4093 & $\mathrm{C} 17-\mathrm{C} 18-\mathrm{C} 20$ & 121.1916 & C4-C5-C6-H10 & -179.3055 \\
\hline C29-C30 & 1.4193 & C17-C18-H21 & 117.9434 & H9-C5-C6-C1 & 179.9418 \\
\hline C29-C31 & 1.4179 & $\mathrm{C} 20-\mathrm{C} 18-\mathrm{H} 21$ & 120.859 & H9-C5-C6-H10 & 0.1358 \\
\hline C30-C32 & 1.4034 & C17-C19-C22 & 120.0855 & C4-N15-N16-C17 & -179.8752 \\
\hline C30-H33 & 1.0892 & C17-C19-H23 & 118.6556 & N15-N16-C17-C18 & 179.9827 \\
\hline C31-C34 & 1.405 & $\mathrm{C} 22-\mathrm{C} 19-\mathrm{H} 23$ & 121.256 & N15-N16-C17-C19 & 0.3605 \\
\hline C32-H37 & 1.0881 & $\mathrm{C} 24-\mathrm{C} 20-\mathrm{H} 25$ & 120.3611 & C19-C17-C18-C20 & -0.2219 \\
\hline C34-C36 & 1.4085 & C19-C22-C24 & 121.0799 & C19-C17-C18-H21 & 178.8959 \\
\hline C34-H38 & 1.088 & $\mathrm{C} 19-\mathrm{C} 22-\mathrm{H} 26$ & 119.8737 & N16-C17-C19-C22 & -179.6555 \\
\hline \multirow[t]{22}{*}{ С $36-\mathrm{H} 39$} & 1.0868 & C24-C22-H26 & 119.0432 & N16-C17-C19-H23 & -0.2614 \\
\hline & & $\mathrm{C} 20-\mathrm{C} 24-\mathrm{C} 22$ & 118.7327 & C18-C17-C19-C22 & 0.7331 \\
\hline & & $\mathrm{C} 20-\mathrm{C} 24-\mathrm{N} 27$ & 123.256 & C18-C17-C19-H23 & -179.8729 \\
\hline & & C22-C24-N27 & 117.9475 & C17-C18-C20-C24 & -0.5144 \\
\hline & & C24-N27-H28 & 115.1051 & C17-C18-C20-H25 & 177.311 \\
\hline & & $\mathrm{A}(24-\mathrm{N} 27-\mathrm{C} 29$ & 129.583 & H21-C18-C20-C24 & -179.6065 \\
\hline & & H28-N27-C29 & 115.307 & H21-C18-C20-H25 & -1.7812 \\
\hline & & N27-C29-C30 & 118.213 & C17-C19-C22-C24 & -0.5147 \\
\hline & & N27-C29-C31 & 123.151 & C17-C19-C22-H26 & 178.8285 \\
\hline & & C30-C29-C31 & 118.5791 & H23-C19-C22-C24 & -179.8927 \\
\hline & & C29-C30-C32 & 120.7397 & H23-C19-C22-H26 & -0.5495 \\
\hline & & C29-C30-H33 & 119.3194 & C18-C20-C24-C22 & 0.7307 \\
\hline & & C32-C30-H33 & 119.9384 & C18-C20-C24-N27 & 177.7619 \\
\hline & & C29-C31-C34 & 120.1231 & H25-C20-C24-C22 & -177.0779 \\
\hline & & C29-C31-H35 & 120.1601 & H25-C20-C24-N27 & -0.0468 \\
\hline & & C34-C31-H35 & 119.6884 & C19-C22-C24-C20 & -0.2209 \\
\hline & & C30-C32-C36 & 120.5653 & C19-C22-C24-N27 & -177.4106 \\
\hline & & C30-C32-H37 & 119.369 & H26-C22-C24-C20 & -179.5694 \\
\hline & & C36-C32-H37 & 120.063 & H26-C22-C24-N27 & 3.2408 \\
\hline & & C31-C34-C36 & 121.1611 & C20-C24-N27-H28 & -154.75 \\
\hline & & C31-C34-H38 & 118.9344 & C20-C24-N27-C29 & 26.0976 \\
\hline & & C36-C34-H38 & 119.9006 & C22-C24-N27-H28 & 22.303 \\
\hline
\end{tabular}




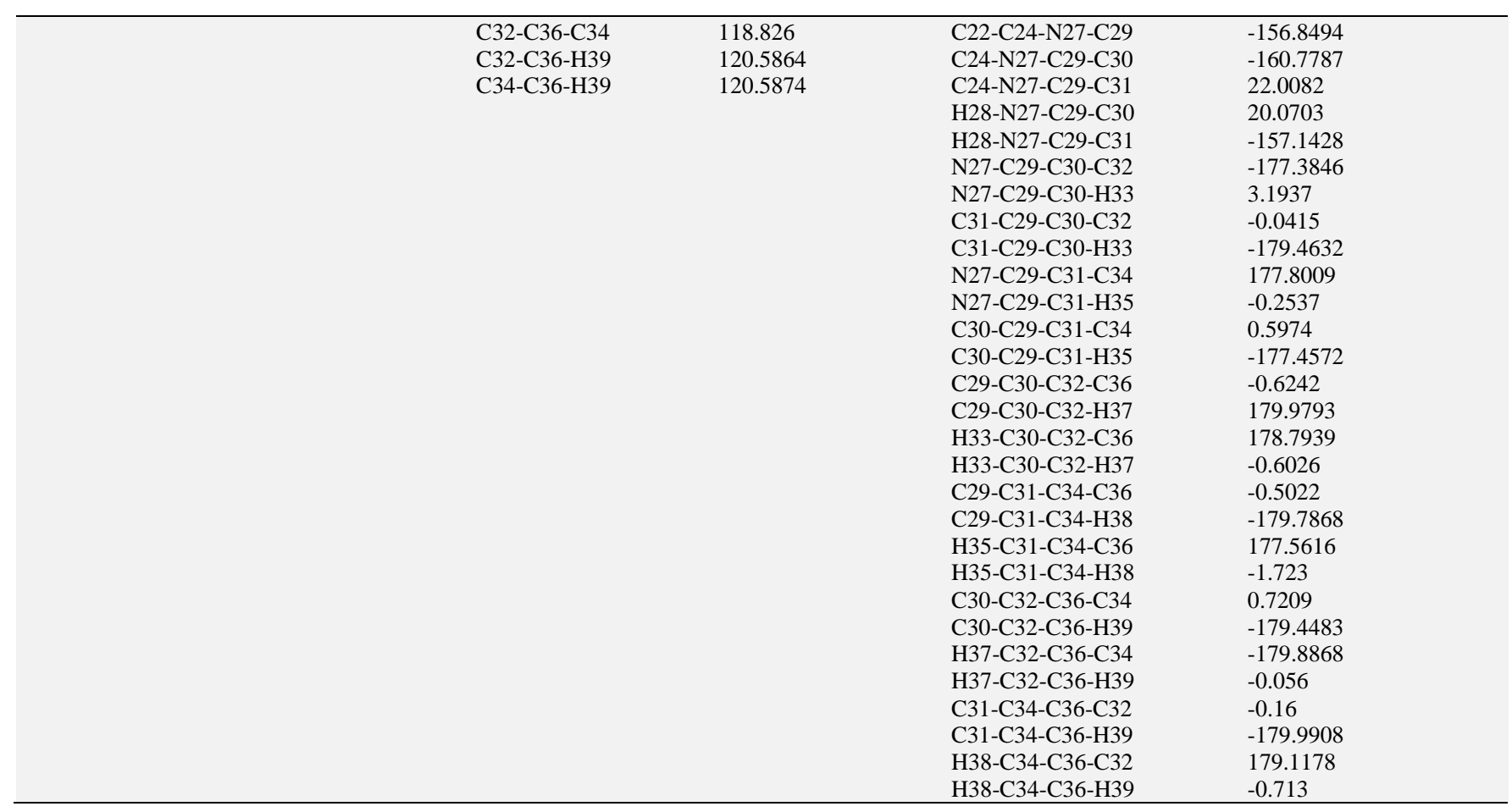

\subsection{Molecular orbital analysis}

The electronic absorption corresponds to the transition from the ground to the first excited state and is mainly described by one electron excitation from the highest occupied molecular orbital (HOMO) to the lowest unoccupied molecular orbital (LUMO). The DFT-B3LYP/ LANL2DZ method was used in order to compute HOMO-LUMO energy gap of metanil yellow. HOMO (Fig. 3.1) and LUMO (Fig. 3.2) which represent the plot of electron density for particular molecule are represented in Fig. 3. The band gap value found out to be $2.17 \mathrm{eV}$ with HOMO energy of $-2.4 \mathrm{eV}$ and LUMO energy of $-0.23 \mathrm{eV}$ from the used exchange correlation functional. The LUMO has an electron acceptor represents the ability to obtain an electron, and HOMO represents the ability to donate an electron. The small value of band gap witnesses the chemical activity of the compound. This also proves the considerable application of metanil yellow as nonlinear optical material.
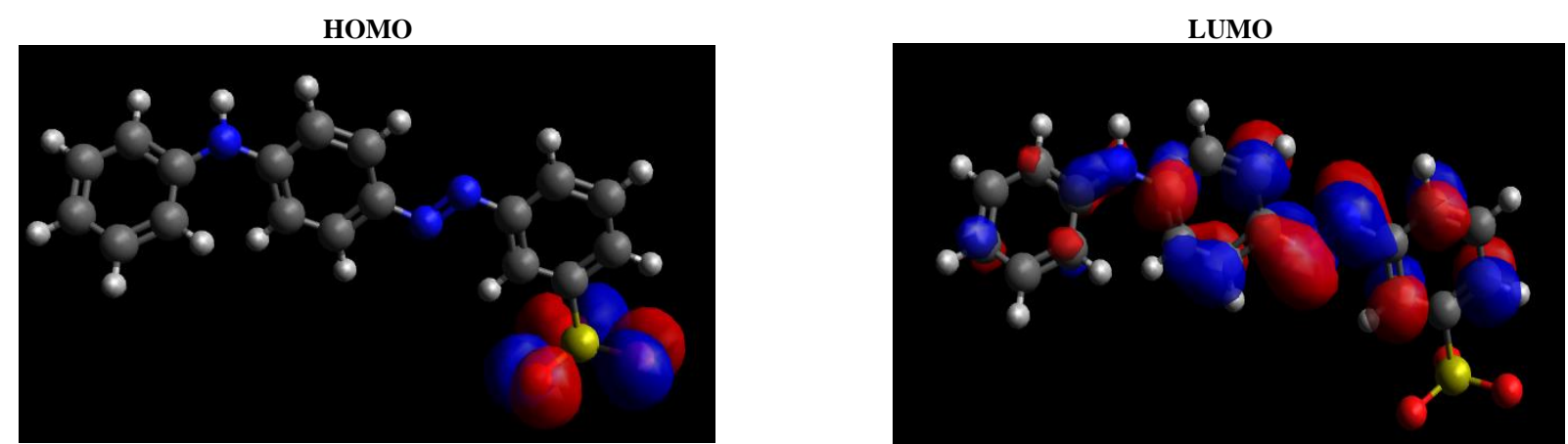

Fig. 3: HOMO-LUMO.

\subsection{Van der walls forces}

The DFT-B3LYP/ LANL2DZ method was used in order to analyse Van der Waals field. This analysis was performed using Avogadro software and the surfaces are shown in Fig. 4.

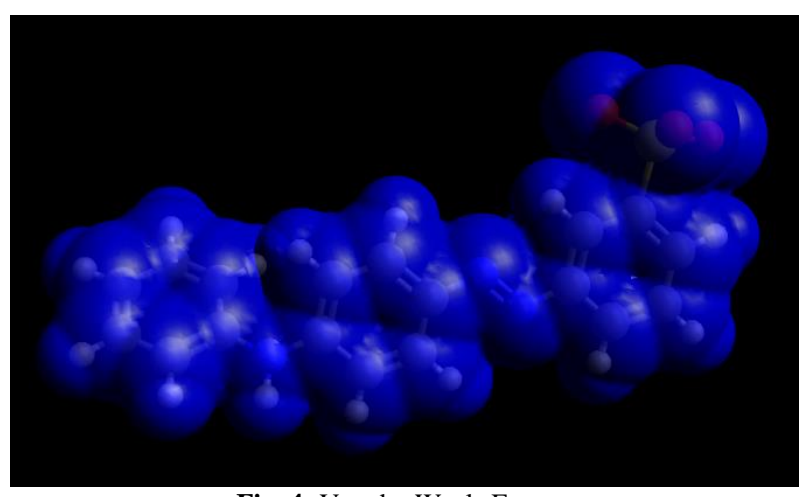

Fig. 4: Van der Waals Forces. 


\subsection{Nonlinear optical properties}

The Dipole moment $\mu$ (D), polarizability and first-order hyperpolarizability of metanil yellow helped us to study nonlinear optical properties (NLO). The dipole moment of the title compound was found out to be $29.1368 \mathrm{D}$. The polarizability and first order hyperpolarizability values of metanil yellow are calculated using equations $(2,3)$ and found out to be -216.7941 a.u. and 1330.0961 a.u. respectively. These properties were obtained using DFT-B3LYP method and LANL2DZ basis set. The considerably high value of dipole moment and hyperpolarizability of the title compound is the proof for the compound to have large NLO optical property. Dipole moment, polarizability and hyperpolarizability of the title compound are summarized in Table 2.

Table 2: Electric Dipole Moment M (D), Polarizability $A_{\text {tot }}\left(X 10{ }^{23}\right.$ Esu) and First Order Hyperpolarizability $B_{\text {tot }}\left(X 10{ }^{23}\right.$ Esu) Values

\begin{tabular}{llll}
\hline Parameter & Value & Paramaeter & Value \\
\hline$\mu \mathrm{x}$ & -27.1971 & $\beta \mathrm{xxx}$ & -1084.7911 \\
$\mu \mathrm{y}$ & 10.4173 & $\beta \mathrm{xxy}$ & 374.42 \\
$\mu \mathrm{z}$ & 0.8644 & $\beta \mathrm{xyy}$ & -127.3888 \\
$\mu(\mathrm{D})$ & 29.1368 & $\beta \mathrm{yyy}$ & 61.4033 \\
$\alpha \mathrm{xx}$ & -316.1288 & $\beta \mathrm{xxz}$ & 0.4295 \\
$\alpha \mathrm{xy}$ & 53.3461 & $\beta \mathrm{xyz}$ & 24.3903 \\
$\alpha \mathrm{yy}$ & -165.1084 & $\beta \mathrm{yyz}$ & 6.9892 \\
$\alpha \mathrm{xz}$ & 10.5545 & $\beta \mathrm{xzz}$ & -41.7747 \\
$\alpha \mathrm{yz}$ & -4.1306 & $\beta \mathrm{yzz}$ & 7.3467 \\
$\alpha \mathrm{zz}$ & -169.1452 & $\beta$ zzzz & 11.394 \\
$\alpha_{\text {tot }}($ a.u $)$ & -216.7941 & $\beta_{\text {tot }}($ a.u $)$ & 1330.0961 \\
\hline
\end{tabular}

\subsection{Vibrational assignments}

The evidence for the charge transfer interaction between the donor and acceptor groups through л- electron movement is provided by the vibrational spectral studies. Metanil yellow consists of 39 atoms and 174 electrons. It is a negatively charged compound with a single multiplicity. Atoms of the title compound have 111 normal modes of vibration. The potential energy distribution (PED) and the contribution of atomic stretches towards Raman frequencies are obtained using VEDA program. Output of VEDA is used in order to get vibrational assignments of the title compound. Table 3 summarizes vibrational frequency assignments of metanil yellow.

The infrared spectra and bulk Raman spectra for metanil yellow are obtained and shown in Fig. 5 and 6 respectively. The $\mathrm{CH}_{3}$ stretching is usually found to have a frequency of $3000 \mathrm{~cm}^{-1}$ (Silverstein et al. 1981). The title compound shows the peak for $\mathrm{CH}_{3}$ stretching at the frequency of $3241 \mathrm{~cm}^{-1}$ which is contributed by $99 \%$ of stretching potential energy. Potential energy distribution using VEDA software is useful for calculating the contribution of stretching potential energy towards the frequency. Similarly the stretch of N-H, N=N, N-C, S-O bond has frequency of $3625,1431,1258,898 \mathrm{~cm}^{-1}$ respectively. The $\mathrm{C}-\mathrm{C}$ bond stretch for aromatic compounds shows the frequency within range 1100 to $1650 \mathrm{~cm}^{-1}$ (Roeges 1994, Clothup et al. 1990). Contribution of each stretch and bends towards Raman frequency is shown in Table 3. For example, consider N-C stretch (s34) for N (atom number 16) and C (atom number 17) - 23\% of the stretching potential energy contributes to $1258 \mathrm{~cm}^{-1}$ vibration and $15 \%$ contributes to $1172 \mathrm{~cm}^{-1}$ vibration. Similarly, the atomic stretches contributing to vibration can be determined. For example, the atomic stretches contributing to $1258 \mathrm{~cm}^{-1}$ can be obtained by comparing stretches of s33, s34, s44 and s50. Thus, atomic stretches contributing to $1258 \mathrm{~cm}^{-1}$ vibration are N16-C17, N15-C4, H8-C3-C2 and H26-C22-C19 in decreasing order of contribution. Also, STRE, BEND, TORS and OUT represents stretching, bending, torsional and out of plane modes respectively.

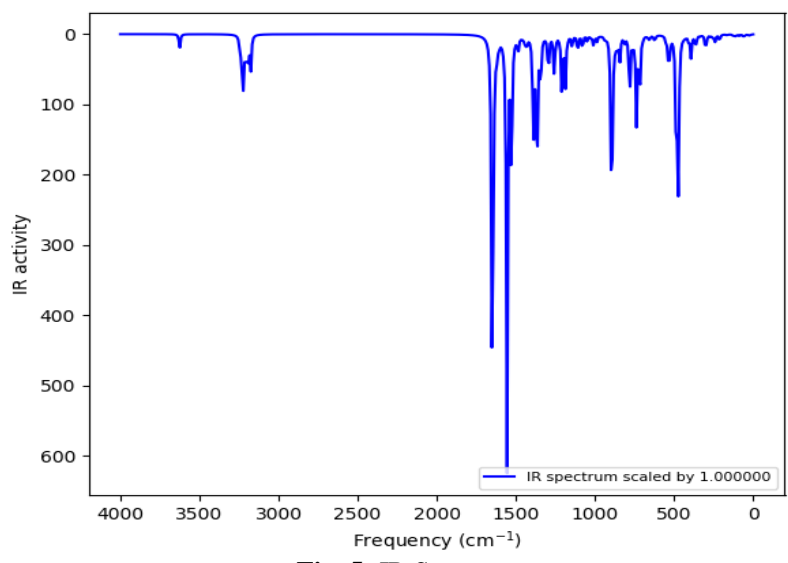

Fig. 5: IR Spectra. 

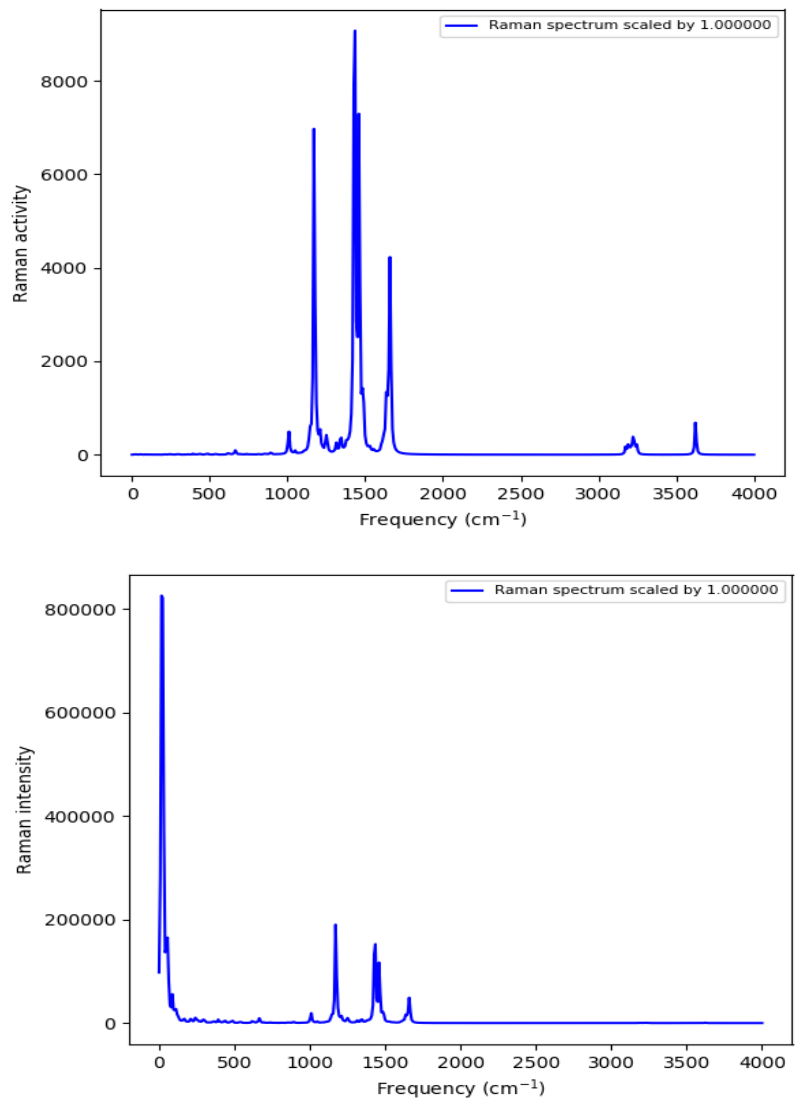

Fig. 6: Raman Spectra.

Table 3: Potential Energy Distribution (PED)

\begin{tabular}{|c|c|c|c|c|c|c|c|}
\hline \multicolumn{8}{|c|}{$\begin{array}{l}\text { Average max. Potential Energy }\langle\mathrm{EPm}\rangle=31.019 \\
\text { TED Above } 100 \text { Factor TAF }=0.000 \\
\text { Average coordinate population } 1.000\end{array}$} \\
\hline s1 & STRE & 27 & 28 & & $\mathrm{NH}$ & 1.013264 & $\mathrm{f} 3625100$ \\
\hline s2 & STRE & 1 & 4 & & $\mathrm{CH}$ & 1.087059 & $\mathrm{f} 322748 \mathrm{f} 321642$ \\
\hline s3 & STRE & 3 & 8 & & $\mathrm{CH}$ & 1.085399 & f324199 \\
\hline s4 & STRE & 5 & 9 & & $\mathrm{CH}$ & 1.087188 & $\mathrm{f} 322726 \mathrm{f} 321655 \mathrm{f} 319119$ \\
\hline s5 & STRE & 6 & 10 & & $\mathrm{CH}$ & 1.087791 & f3227 $25 \mathrm{f} 319172$ \\
\hline s6 & STRE & 18 & 21 & & $\mathrm{CH}$ & 1.086548 & f3240 $20 \mathrm{f} 321967$ \\
\hline s8 & STRE & 20 & 25 & & $\mathrm{CH}$ & 1.084430 & $\mathrm{f} 324731 \mathrm{f} 324036 \mathrm{f} 321929$ \\
\hline s9 & STRE & 22 & 26 & & $\mathrm{CH}$ & 1.089591 & $\mathrm{f} 317592$ \\
\hline s10 & STRE & 30 & 33 & & $\mathrm{CH}$ & 1.089238 & $\mathrm{f} 320316 \mathrm{f} 319211 \mathrm{f} 317666$ \\
\hline s11 & STRE & 31 & 35 & & $\mathrm{CH}$ & 1.084298 & $\mathrm{f} 324754 \mathrm{f} 324030$ \\
\hline s12 & STRE & 32 & 37 & & $\mathrm{CH}$ & 1.088067 & $\mathrm{f} 322521 \mathrm{f} 320346 \mathrm{f} 317625$ \\
\hline s13 & STRE & 34 & 38 & & $\mathrm{CH}$ & 1.087963 & f3203 30 f3192 50 \\
\hline s14 & STRE & 36 & 39 & & $\mathrm{CH}$ & 1.086844 & $\mathrm{f} 322555 \mathrm{f} 319231$ \\
\hline s15 & STRE & 3 & 2 & & $\mathrm{CC}$ & 1.393437 & $\mathrm{f} 163721 \mathrm{f} 139114$ \\
\hline s17 & STRE & 22 & 19 & & $\mathrm{CC}$ & 1.396432 & $\mathrm{f} 166116 \mathrm{f} 164814 \mathrm{f} 144515$ \\
\hline s18 & STRE & 2 & 1 & & $\mathrm{CC}$ & 1.404736 & f1637 $10 \mathrm{f} 148812 \mathrm{f} 139114 \mathrm{f} 110912 \mathrm{f} 107912$ \\
\hline s19 & STRE & 6 & 5 & & $\mathrm{CC}$ & 1.404275 & f1637 $14 \mathrm{f} 139114 \mathrm{f} 110917$ \\
\hline s20 & STRE & 20 & 18 & & $\mathrm{CC}$ & 1.401879 & f1445 13 \\
\hline $\mathrm{s} 21$ & STRE & 30 & 32 & & $\mathrm{CC}$ & 1.403447 & f1661 $15 \mathrm{f} 164815 \mathrm{f} 111214$ \\
\hline $\mathrm{s} 22$ & STRE & 1 & 6 & & $\mathrm{CC}$ & 1.408939 & $\mathrm{f} 160835 \mathrm{f} 118711 \mathrm{f} 107918 \mathrm{f} 100810$ \\
\hline s23 & STRE & 34 & 31 & & $\mathrm{CC}$ & 1.404998 & f1112 13 \\
\hline s24 & STRE & 32 & 36 & & $\mathrm{CC}$ & 1.409143 & f1112 $10 \mathrm{f} 104926$ \\
\hline s25 & STRE & 36 & 34 & & $\mathrm{CC}$ & 1.408547 & f1638 15 f1049 21 \\
\hline s26 & STRE & 4 & 5 & & $\mathrm{CC}$ & 1.414483 & $\mathrm{f} 163720 \mathrm{f} 160810 \mathrm{f} 148810 \mathrm{f} 139116$ \\
\hline s27 & STRE & 18 & 17 & & $\mathrm{CC}$ & 1.411428 & $\mathrm{f} 164811 \mathrm{f} 162216$ \\
\hline s28 & STRE & 19 & 17 & & $\mathrm{CC}$ & 1.417783 & $\mathrm{f} 138011$ \\
\hline s29 & STRE & 24 & 20 & & $\mathrm{CC}$ & 1.415883 & f1622 $23 \mathrm{f} 138017 \mathrm{f} 129411$ \\
\hline s30 & STRE & 31 & 29 & & $\mathrm{CC}$ & 1.417860 & $\mathrm{f} 163816 \mathrm{f} 138010 \mathrm{f} 129410$ \\
\hline s31 & STRE & 27 & 29 & & $\mathrm{NC}$ & 1.409294 & $\mathrm{f} 136616 \mathrm{f} 124815$ \\
\hline s32 & STRE & 27 & 24 & & $\mathrm{NC}$ & 1.413809 & f1555 $10 \mathrm{f} 124819$ \\
\hline s33 & STRE & 15 & 4 & & $\mathrm{NC}$ & 1.427274 & $\mathrm{f} 125812 \mathrm{f} 120915$ \\
\hline s36 & STRE & 11 & 14 & & SO & 1.646919 & f898 $59 \mathrm{f} 73823$ \\
\hline s37 & STRE & 11 & 12 & & SO & 1.650425 & f893 $47 \mathrm{f} 73825$ \\
\hline s38 & STRE & 11 & 2 & & $\mathrm{SC}$ & 1.901641 & $\mathrm{f} 25310 \mathrm{f} 24036$ \\
\hline s39 & BEND & 22 & 19 & 17 & $\mathrm{CCC}$ & 120.09 & $\mathrm{f} 102538 \mathrm{f} 65514$ \\
\hline
\end{tabular}




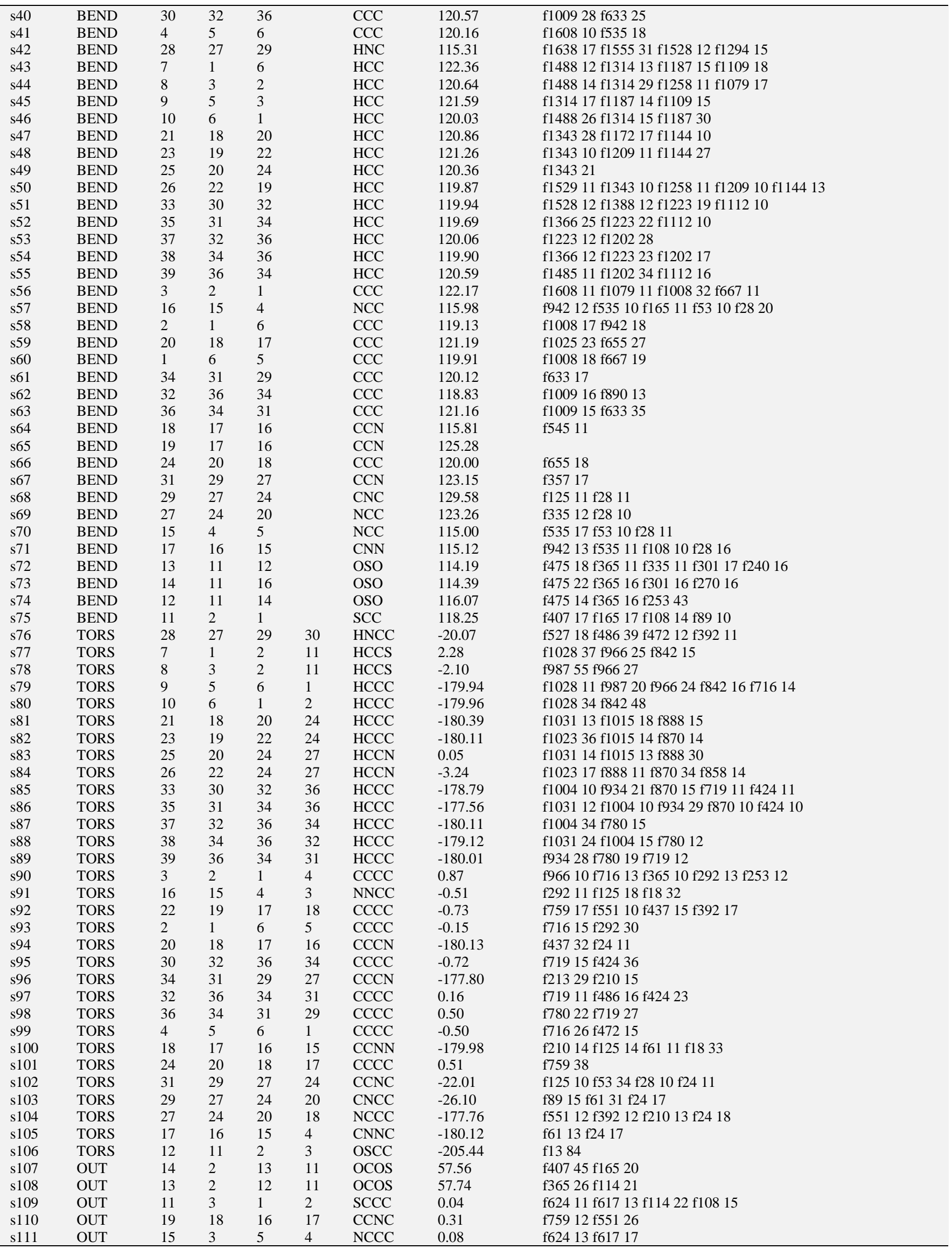

\subsection{Global chemical reactivity parameters and thermodynamic parameters}

The energy values of HOMO and LUMO are useful in calculating ionization potential, electron affinity of the title compound. The HOMO and LUMO energies were obtained from DFT calculations using B3LYP exchange correlation hybrid functional and LANL2DZ basis set. The values of electronegativity, electrophilicity index, chemical potential, etc. for metanil yellow can be calculated theoretically. These values of global chemical reactivity descriptors of compounds are listed in Table 4. Ionization potential and electron affinity of 
the title compound are 2.4 and 0.23 respectively. Other general chemical reactivity parameters were also obtained from these values. The thermochemistry and thermodynamic parameters are also listed in Table 5. The negative value of the chemical potential is fair enough for proving that the title compound is thermodynamically stable.

Table 4: Global Reactivity Parameters

\begin{tabular}{llll}
\hline Parameter & Value & Parameter & \\
\hline$\mu(\mathrm{D})$ & 29.1368 & $\mathrm{I}$ & Value \\
$\alpha$ tot (a.u) & -216.7941 & A & 2.4 \\
Btot (a.u) & 1330.0961 & $\mu$ & 0.23 \\
HOMO (eV) & -2.4 & $\chi$ & -1.315 \\
LUMO (eV) & -0.23 & $\eta$ & 1.315 \\
$\Delta \mathrm{E}(\mathrm{eV})$ & 2.17 & $\mathrm{~S}$ & 1.085 \\
& & $\omega$ & 0.5425 \\
& & 0.7969 & \\
\hline
\end{tabular}

Table 5: Thermodynamic Parameters

\begin{tabular}{lc}
\hline Zero-point correction (Hartree/Particle) & 0.289055 \\
\hline Thermal correction to Energy & 0.310416 \\
Thermal correction to Enthalpy & 0.311361 \\
Thermal correction to Gibbs Free Energy & 0.234368 \\
Sum of electronic and zero-point Energies & -1093.762182 \\
Sum of electronic and thermal Energies & -1093.740821 \\
Sum of electronic and thermal Enthalpies & -1093.739877 \\
Sum of electronic and thermal Free Energies & -1093.816869 \\
\hline
\end{tabular}

\subsection{UV-Vis spectra and density of states}

The UV-Vis spectra and DOS were obtained from DFT calculations using B3LYP exchange correlation hybrid functional and LANL2DZ basis set. GaussSum software was used to plot the UV-Vis spectra and Density of state spectrum shown in Fig. 7. The bandgap obtained from the energies of frontier molecular orbitals is represented in Table 4. This bandgap is compared with the energy gap obtained from the UV- Vis spectra and found out to be equal in value.

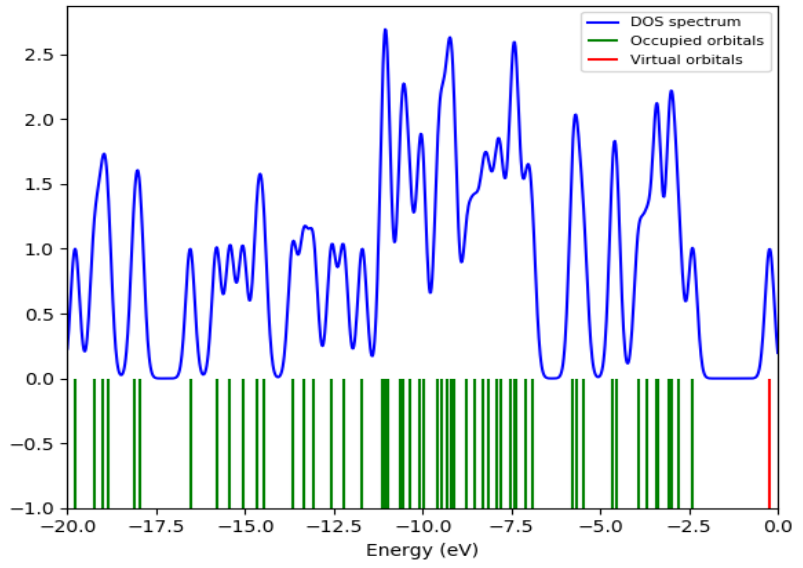

Fig. 7: UV-Vis Spectra and DOS.

\subsection{Atomic charges and population analysis}

Obtained Mulliken charges and atomic tensors for each atom is listed in Table 6. The maximum atomic charge is obtained for S11 when compared with other atoms. This is due to the attachment of negatively charged carbon $\mathrm{O} 12, \mathrm{O} 13$ and $\mathrm{O} 14$ atoms.

Table 6: Atomic Charges and Population Analysis

\begin{tabular}{|c|c|c|c|c|c|c|c|c|}
\hline atoms & Mulliken & APT & atoms & Mulliken & APT & atoms & Mulliken & APT \\
\hline $\mathrm{C} 1$ & -0.224792 & -0.103019 & O14 & -0.6676 & -0.7461 & N27 & -0.51547 & -1.30619 \\
\hline $\mathrm{C} 2$ & -0.062626 & -0.270089 & N15 & -0.13209 & 0.169405 & $\mathrm{H} 28$ & 0.286834 & 0.163811 \\
\hline $\mathrm{C} 3$ & -0.274698 & -0.084429 & N16 & -0.09993 & 0.045425 & $\mathrm{C} 29$ & 0.438544 & 0.82866 \\
\hline $\mathrm{C} 4$ & 0.181457 & -0.19144 & $\mathrm{C} 17$ & 0.153932 & -0.14387 & C30 & -0.43434 & -0.30039 \\
\hline C5 & -0.350928 & 0.021293 & $\mathrm{C} 18$ & -0.34374 & 0.113855 & C31 & -0.37048 & -0.21176 \\
\hline C6 & -0.18816 & -0.101795 & $\mathrm{C} 19$ & -0.27424 & 0.066879 & C32 & -0.18862 & 0.103062 \\
\hline $\mathrm{H} 7$ & 0.281979 & 0.113096 & $\mathrm{C} 20$ & -0.36174 & -0.24584 & H33 & 0.214447 & 0.042853 \\
\hline H8 & 0.309696 & 0.128211 & $\mathrm{H} 21$ & 0.254422 & 0.077315 & C34 & -0.20785 & 0.116079 \\
\hline H10 & 0.210963 & -0.008475 & $\mathrm{H} 23$ & 0.266749 & 0.088918 & C36 & -0.25953 & -0.23727 \\
\hline $\mathrm{S} 11$ & 1.072248 & 1.641824 & $\mathrm{C} 24$ & 0.456171 & 0.887487 & H37 & 0.211231 & 0.013577 \\
\hline $\mathrm{O} 12$ & -0.675525 & -0.800213 & $\mathrm{H} 25$ & 0.252463 & 0.045143 & H38 & 0.216441 & 0.031445 \\
\hline $\mathrm{O} 13$ & -0.671589 & -0.773228 & $\mathrm{H} 26$ & 0.211628 & 0.013137 & H39 & 0.216232 & 0.025865 \\
\hline
\end{tabular}

\section{Conclusion}

In this work, detail quantum chemical study of metanil yellow was done. Density Functional Theory (DFT) was used in analysing the geometrical optimization of metanil yellow using B3LYP exchange correlation functional and LANL2DZ basis set in order to obtain 
bond lengths and bond angles. The Vibrational analysis consisting of Vibrational wavenumbers, Raman intensities, vibrational frequencies, IR intensities and force constant were computed. DFT was used in order to calculate dipole moment, polarizability and first-order hyperpolarizability of the studied compound. The total surface analysis along with potential energy distribution was also studied for the titled compound. The density of state analysis was done in order to obtain the energy contribution of each electron. HOMO-LUMO orbital energies were calculated and lowering of HOMO-LUMO energy gap explains the charge transfer interactions taking place within the molecule. These HOMO-LUMO energies can be used for obtaining some molecular properties such as electron affinity, ionization potential, chemical potential, etc. of the title compound. In the end, all these results showed that the title compound exhibits considerable NLO properties.

\section{References}

[1] Dhakal S, Chao K, Schmidt W, Qin J, Kim M \& Chan D (2016), Evaluation of Turmeric Powder Adulterated with Metanil Yellow using FTRaman and FT-IR Spectroscopy. Foods 5 (2), 36. DOI: https://doi.org/10.3390/foods5020036.

[2] "Common food adulterants in India", India Today, New Delhi, October 19, 2018. Available at: https://www.indiatoday.in/education-today/gkcurrent-affairs/story/common-food-adulterants-in-india-1370601-2018-10-19.

[3] Nath PP, Sarkar K, Mondal M \& Paul G. (2016), Metanil yellow impairs the estrous cycle physiology and ovarian folliculogenesis in female rats. Environ Toxicol 31, 2057-67. https://doi.org/10.1002/tox.22205.

[4] Ghosh D, Singha PS, Firdaus SB \& Ghosh S, (2017), Metanil yellow: The toxic food colorant 4(4), 65-66. https://doi.org/10.21276/apjhs.

[5] Hazra S, Dome RN, Ghosh S \& Ghosh D. (2016), Protective effect of methanolic leaves extract of Coriandrum sativum against metanil yellow induced lipid peroxidation in goat liver: An in vitro study. Int J Pharmacol Pharma Sci, 3(5), 34-41.

[6] Sarkar R. (2013), Histopathological changes in the brain of metanil yellow treated albino rat (Rattus norvegicus). Int J Basic App Med Sci 2013; 3:256-8.

[7] Das M, Ramchandani S, Upreti RK \& Khanna SK (1997), Metanil Yellow: a Bifunctional Inducer of Hepatic Phase I and Phase II Xenobiotic Metabolizing Enzymes. Food and Chemical Toxicology 35 (8), 835-838. https://doi.org/10.1016/S0278-6915(97)00047-1.

[8] Frisch MJ, et al., (2009), Gaussian 09, Revision B.01, Gaussian Inc., Wallingford CT.

[9] Lee C, Yang W \& Parr RG (1988), Development of the Colle-Salvetti correlation energy formula into a functional of the electron density. Physical Review B 37 (2), 785-789. https://doi.org/10.1103/PhysRevB.37.785.

[10] Arivazhagan M \& Jeyavijayan S (2011), Vibrational spectroscopic, first-order hyperpolarizability and HOMO, LUMO studies of 1, 2-dichloro-4 nitrobenzene based on Hartree-Fock and DFT calculations. Spectrochimica Acta Part A: Molecular and Biomolecular Spectroscopy 79 (2), 376 383. https://doi.org/10.1016/j.saa.2011.03.036.

[11] Becke AD (1993), Density-functional thermochemistry. III. The role of exact exchange. The Journal of Chemical Physics 98(7), 5648-5652. DOI: https://doi.org/10.1063/1.464913.

[12] Dunning TH Jr. \& Hay PJ (1977), In: "Modern Theoretical Chemistry”, Ed H F. Schaefer III, Vol. 3 (Plenum, New York, 1977) 1-28.

[13] Hay PJ \& Wadt WR (1985), Ab initio effective core potentials for molecular calculations - potentials for the transition-metal atoms Sc to Hg. J. Chem. Phys., 82, 270-83. https://doi.org/10.1063/1.448799.

[14] Frisch E, Hratchian HP, Dennington II RD, Keith TA, Millam J, Nielsen B, Holder AJ \& Hiscocks J (2009), Gaussian, Inc. GaussView Version 5.0.8, Wallinford, CT.

[15] Hanwell MD, Curtis DE, Lonie DC, Vandermeersch T, Zurek E \& Hutchison GR (2012), Avogadro: an advanced semantic chemical editor, visualization, and analysis platform. Journal of Cheminformatics volume 4, Article number: 17. https://doi.org/10.1186/1758-2946-4-17.

[16] Jamroz MH (2004), Vibrational Energy Distribution Analysis: VE-DA 4 Program. Warsaw, Poland.

[17] O'Boyle NM, Tenderholt AL \& Langner KM (2008), cclib: A library for package-independent computational chemistry algorithms. J. Comp. Chem. 29, 839-845. https://doi.org/10.1002/jcc.20823.

[18] Ferreira MMC (1993), Population analysis from atomic polar tensors. Journal of Molecular Structure 294, 75-78. DOI: https://doi.org/10.1016/0022-2860(93)80318-P.

[19] Koopmans \& Tjalling (1934), Über die Zuordnung von Wellenfunktionen und Eigenwerten zu den einzelnen Elektronen eines Atoms. Physica. 1 (1-6), 104- 113. https://doi.org/10.1016/S0031-8914(34)90011-2.

[20] Zhang, Gang, Musgrave \& Charles B. (2007), Comparison of DFT Methods for Molecular Orbital Eigenvalue Calculations. The Journal of Physical Chemistry A 111 (8), 1554-1561. https://doi.org/10.1021/jp061633o.

[21] Parr RG, Donnelly RA, Levy M \& Palke WE (1978), Electronegativity: the density functional viewpoint. Journal of Chemical Phys-ics 68(8), 3801-3807. https://doi.org/10.1063/1.436185.

[22] Parr RG \& Pearson RG (1983), Absolute hardness: companion pa-rameter to absolute electronegativity. Journal of the American Chemical Society 105(26), 7512-7516. https://doi.org/10.1021/ja00364a005.

[23] Parr RG, Szentpály LV \& Liu S (1999) Electrophilicity Index. Journal of the American Chemical Society 121(9), 1922-1924. DOI: https://doi.org/10.1021/ja983494x.

[24] Pearson RG (2005) Chemical hardness and density functional theory. Journal of Chemical Sciences 117(5), 369-377. DOI: https://doi.org/10.1007/BF02708340.

[25] Silverstein RM, Basseler GC \& Morill C (1981) Spectrometric Identification of Organic Compounds, Wiley, New York. DOI: https://doi.org/10.1002/oms.1210260923.

[26] Roeges NPG (1994) A Guide to the Complete Interpretation of IR Spectra of Organic Compounds, Wiley, New York.

[27] Clothup NB, Daly LH \& Wiberly SE (1990) Introduction to IR and Raman Spectroscopy, Academic Press, New York. 